The European Journal of

Humour Research 8 (2) 49-61 www.europeanjournalofhumour.org

\title{
Cartoons in Romanian humorous news
}

\section{Commentary piece}

\author{
Andreea-Nicoleta Soare \\ University of Bucharest, Romania \\ Andreea-nicoleta.soare@drd.unibuc.ro
}

\begin{abstract}
Studying cartoons in Romanian humorous news is a great way to underline the diversity of humour's mechanisms and construction. The common topic of cartoons in Romanian media is politics, but there are also a great number of cartoons exploring subjects such as art, science, society or famous people. Unlike verbal humour, wherein incongruities are text-based, in cartoons, incongruities can emerge through the interaction of image and text, between two elements in the image, or even between the texts in the balloons (Hempelmann \& Samson 2008). The present study aims at analysing how humour emerges differently, depending on their topic, in cartoons created by the Romanian humorous media websites Times New Roman and Academia Catavencu, as these have been the two of the most controversial humorous news websites for quite some time. I intend to argue that, when it comes to political cartoons, the methods of humour are quite complex, equally relying on the image and the text, using polysemy, paronymy or syllepsis to create humour, while cartoons about society or gossip are usually based on implicitness and exaggeration, mostly found in images and symbols, as the targeted topics or people do not require such a complex background in order to make readers laugh. I have also observed that cartoons that rely less on text have more powerful symbols, which are full of various significations that help the readers make all the necessary connections to correctly interpret the image.
\end{abstract}

Keywords: humour, cartoons, hyperunderstanding, nonunderstanding, implication.

\section{Introduction}

Within humorous media, journalists do not use only verbal humour to express their thoughts on certain political and social attitudes, but also cartoons. Cartoons have a long history within Romanian media, starting in 1860 and aiming at making people laugh at society's shortcomings. During the communist period, they were rather a method used by artists to fight against 
repression and censorship. With the fall of the communist bloc, after 1989, caricaturists started to use cartoons to express their feelings on how Romanian people were embracing freedom and later on to underscore Romanians' habits, whether they are talking about politics, social affairs, etc.

Media cartoons are drawings that illustrate, exaggeratedly and deformedly, well-known individuals or events in one country's culture or worldwide, aiming at underscoring certain opinions regarding their actions. There are image-based cartoons, but also cartoons wherein images are accompanied by texts (often in balloons), aimed at offering more details that usually give a better interpretation and, implicitly, enhancing their meaning (Hempelmann \& Samson 2008). Some specialists have studied the interaction of both visual and verbal humour in cartoons, concluding that these two semiotic modes enhance the humorous effect or produce it through the juxtaposition of the visual and verbal elements (for more see Tsakona 2009: 1177). Indeed, as I will show in this analysis, there are cartoons relying more on the textual side, some on images, and others on both. Therefore, as humorous texts and cartoons are some of the most common methods journalists use to comment on different political or social events, I found it important to analyse how Romanian cartoons are creating a humorous effect, in a society that always knew how to laugh even about dramatic matters. It is also important to observe how the humorous effect is created in political cartoons - as complex topics require more complex textual and visual processes - and in cartoons about people's habits or everyday events, which mostly focus on symbols.

Cartoon topics range from politics, to daily life, art, sports, religion, famous people etc., and their form changes depending on the topic. In political cartoons, the text placed inside the balloons is essential for the correct interpretation of the message, while in cartoons related to social issues, the message can be correctly interpreted only through images, as the events and the targeted people are easy to recognise because their referents are usually well-known to readers. Also, the message transmitted through political cartoons aims at persuading ${ }^{1}$ and provoking a certain reaction, while cartoons about social issues only aim at making people laugh:

A cartoon is an illustration, usually in a single panel, published in the editorial or comments pages of a newspaper. Generally, the purpose of a political cartoon is to represent an aspect of social, cultural or political life in a way that condenses reality and transforms it in a striking, original and/or humorous way.

(El Refaie 2009:175, in Alousque 2014: 66)

Studies in cartoons (Hempelmann and Samson, 2008) have underlined some differences between written humour and visual humour, and the first one is their construction. In verbal humour, the speaker must choose his/her words wisely and have a clear and linear discourse, because these are the only elements the hearer has access to when interpreting the joke. But, in

\footnotetext{
${ }^{1}$ Although the initial purpose of cartoons was, and in a way still is, highlighting different shortcomings in politics and society and, implicitly, provoking a reaction from the audience, lately we seem to be dealing with different perspectives on this matter. Millennials are the target of all this humoristic news, whether we are talking about cartoons or traditional news. Hence, there are studies talking about slaktivism (McClennen \& Maisel 2014), a term used to define millennials' activism through the internet, starting with humoristic news, which makes them realise certain gaps in terms of politics and leads to their taking a stance through the Internet. However, there are recent studies that focus on clicktivism, which refers to political passivity as a characteristic of millennials (White 2010, in Brock 2018: 283). Jokes about politics are seen as "thermometers that measure, record and indicate that is going on" (Davies, 1990: 9 in Brock 2018: 284), and, although millennials are consumers and promoters of these jokes, they are not taking part in any kind of protest or activism again the targets of these jokes; they are only reading the jokes, appreciating them and forwarding them to others.
} 
visual humour, like the image-based cartoons, there is no linearity in their processing; therefore, artists can be more creative in the use of stylistic elements to send their message. However, various stylistic elements are also subjected to interpretation: colours, shapes, the position of elements, their contour, etc. On the other hand, in media cartoons, readers have access to characters' facial expressions. Hence, they interpret their feelings easier than when dealing with written humour. In addition, in verbal humour, incongruity is, most of the times, placed in the first part of the joke and its resolution in the second part. But for cartoons, incongruity can be placed differently from one image to another: between text and image, between two meanings in one image, between texts in balloons. The relation between text and image is essential to reach a humorous effect. Very often, we are talking about visual metaphors (El Rafaie, 2004), which are a combination of visual and verbal signs, leading to one idea only. When this relation creates incongruity, a humorous effect emerges.

For the message of a cartoon to be correctly interpreted, it has to convey information necessary for readers to correctly interpret it: "cartoons are like single sentences: in order to understand them you need to have some extra-textual information" (Saraceni 2003: 36, in Bounegru \& Forceville 2011: 4). Hence, there is an intra-textual context referring to the information the cartoon is offering, whether in the balloons or in the image, and an extra-textual context, referring to the information the reader must know about the targeted individuals (shared knowledge).

The interpretation of a cartoon is a complex process that requires the reader to create a story with the elements the caricaturist uses in the cartoon. Then, after the story is complete, the reader must find its referent in the real world. Cartoons are narrative images; hence, it is important for readers to consider both the visual lexis of a cartoon and the visual syntax. The visual syntax may often be more flexible than its verbal equivalent as it relies more on reader's imagination and associations (Hussein 2019: 455).

The six knowledge resources developed within General Theory of Verbal Humour, namely language, narrative strategy, target, situation, logic mechanism and scripts opposition (see Attardo 2001) will help me account for how verbal and visual humour are created in Romanian cartoons. Besides that, the MDA approach is extremely useful particularly for the interpretation of cartoons on social issues, where cartoons rely mostly on symbols, some of them having no text at all. The multimodal approach (MDA) is a method that combines the linguistic analysis and the analysis of semiotic elements such as images and gestures (Hussein, 2019).

\section{Data of the study}

I will be analysing cartoons from Times New Roman (www.timesnewroman.ro) and Academia Catavencu (www.academiacatavencu.ro) as these are two of the most popular humorous news websites in Romania, but also the only ones to actually create typical cartoons and that have not yet started to use what we today call memes, that is, "a unit of cultural transmission, or a unit of imitation" (Dawkins 1976: 192).

Times New Roman presents its cartoons in a separate section, called "Ovi's category", while the cartoons made by Academia Catavencu's caricaturist, Vali Ivan, are presented randomly on the website, along with the usual humorous news. ${ }^{2}$ Besides creating typical cartoons, these humorous news websites also use images which are a combination between typical cartoons and memes, to support and enhance the meaning of their humorous texts.

Still, in this study, I will be only analysing their typical cartoons and how these are differently created depending on the addressed topic, hence a distinction between cartoons on

\footnotetext{
${ }^{2}$ I managed to get the approval of Times New Roman's caricaturist to use his cartoons. However, I could not reach any of the journalists at the Academia Catavencu journal.
} 
politics and politicians and cartoons on social issues and gossip would better support the purposes of this study. The dataset examined consists of five cartoons on politics and politicians and four on social issues and gossip. Due to copyright reasons, I will reproduce only the Times New Roman cartoons and describe the cartoons from the Academia Catavencu.

\title{
3. Cartoons in humorous news
}

Times New Roman and Academia Catavencu, humorous news websites, are parodying the daily news in the traditional Romanian media, making fun both of the approached topics and the journalists for how they address them. Humorous news follows the same textual structure and online representation as the traditional ones, but it deforms and exaggerates the information, resulting in a mix between information -as there is a strong intertextual link between the original news and the parodied news- and humour -through humour mechanisms such as puns (punning twists) or mechanisms such as non-understanding and hyper-understanding.

Cartoons are part of the humorous news websites, which often use not only humour, but also parody, satire or pastiche to fulfil the journalists' purposes. The relation between the source and the humorous/parodied version is highly important because the allusion to the source marks its shift from humorous comments to humorous news:

\begin{abstract}
Intertextual mechanisms are intensified and exploited in parody for the purpose of showing an altered imitation of the parodied referent with various communicative intentions. That is why, although it is recognised that parody has its own meaning in the first reception process, that meaning is never the definitive one. Parody acquires its ultimate meaning in relation to its model thanks to an ironic intertwining between an implicit text and another implicit one. The aim is not to replace one text by another, neither to destroy it; the aim is to evoke it.
\end{abstract}

(Mendez-Ga de Paredez 2013: 98)

Hence, these texts are not just comments upon traditional media, but actually provide the reader some information about real facts and people, pushing the audience towards critical thinking, and not just making them laugh.

Humorous news has been described in various forms and has received many definitions. Some of these are infotainment (Stockewell 2004), mock news (Newman 2010), faux news or fake news (Saltzman 2007) or satirical news (McClennen \& Maisel 2014). The news and cartoons developed by Times New Roman and Academia Catavencu satirists are also examples of news that mixes information and humour; thus, the term I will be using in this study will be humorous news.

I will be analysing cartoon texts and images depending on their topic. Therefore, I will firstly address the humorous news related to politics and politicians, and then that on social issues and gossip. Each of these two sections discusses humour mechanisms such as polysemy, implicature, hyper-understanding and non-understanding. However, the transition from serious topics (such as politics) to random subjects (such as showbiz) will be marked textually, as political cartoons are mostly based on text and social cartoons rely more on symbols.

\subsection{Politics and politicians}

Cartoons about politicians are the most successful ones in Romanian media. By creating cartoons about certain political people or political events, caricaturists are showing their stances on political affairs. Political cartoons ask for a deeper understanding of the extra-textual context comparing to those related to social issues or gossip, because they are targeting political parties, political events, alliances, or even conflicts on certain laws. For example, in order to get the 
right message from a political cartoon, you cannot just superficially know the target. Instead, you need to know which party he/she belongs to and the party's main principles, objectives, etc. Otherwise, the message will be incorrectly interpreted, and therefore, humour will fail. Alousque (2013) identified various elements specific to political cartoons: they are often more descriptive, they refer to a political-social situation and point to recent events (hence readers must know something about the subject), the targeted events are combined with unrealistic elements, cartoons are critical and use metaphors to convey their messages.

The humour mechanism most often used to create political cartoons seems to be puns, as the words with two different meanings provoke confusion for some of caricaturists' political targets; so, the pun becomes the perfect way of underlining their incompetence.

\subsubsection{Polysemy}

There are two ways caricaturists use polysemy when creating their cartoons: 1) within balloon texts, or 2) between the word in the balloons and image meaning.

The first cartoon discussed here presents former Prime Minister Viorica Dancila and Liviu Dragnea, the former Head of the Social Democratic Party. Dancila is the first female Prime Minister in Romania's history, but also the one to get the most attention from the media so far, due to her grammatical mistakes during live speeches and her unusual gestures made at official meetings with world leaders. Dragnea is the former Head of the Social Democratic Party, who is also getting media attention because of his bad decisions regarding the future of the state and his hidden business involving corruption and nepotism. Many Romanian newspapers have claimed that Liviu Dragnea helped Viorica Dancila become Prime Minister just to lead the country through her, as she is an extremely weak person. In July 2018, the Ministry of Economy announced Dancila's administration would raise pension levels, but political analysts claimed it was only a strategy to get more sympathisers, as there were not enough funds to actually support such a decision.

In Figure 1, polysemy is both used within the text and the image, through the word dot (rom. punct). The first meaning that gets activated in this cartoon is the one seen in the image, which is the visual representation of the punctuation mark emerging as a consequence of the faulty reasoning of the Prime Minister Viorica Dancila, who is the target of humour. The second meaning refers to a political procedure, part of the Pension Scheme, called the pension dot. Another humour resource presented in this cartoon is the syllepsis of the word increase, as, according to this cartoon, by increasing the pension dot the prime minister thinks she has to actually make the dot bigger on paper, and not raise people's pension level. Humour here comes from Viorica Dancila's supposed misinterpretation when using the word dot wrongly. Caricaturists point out her "limited" intellectual capacity, representing her as inappropriate for the position she has. The position of the two characters in the cartoon suggests a professorstudent or director-subordinate type of relation, as Dragnea points the finger to Dancila, thus revealing how their relationship actually works: one gives the orders and the other obeys. This picture addresses the targets directly, as the caricaturists use a direct address for the identification of Dancila "What are you doing, Mrs. Dancila?" And for Dragnea's identification, they created a character that looks perfectly like him.

The narrative strategy used here is news cartoons, the logical mechanism is the false analogy, frequently used in cartoons; the opposed scripts are real-absurd, smart-stupid; the situation involves the announcement made by the Ministry of Economy on pensions' increase in July 2018; and the target is prime-minister Dancila. 


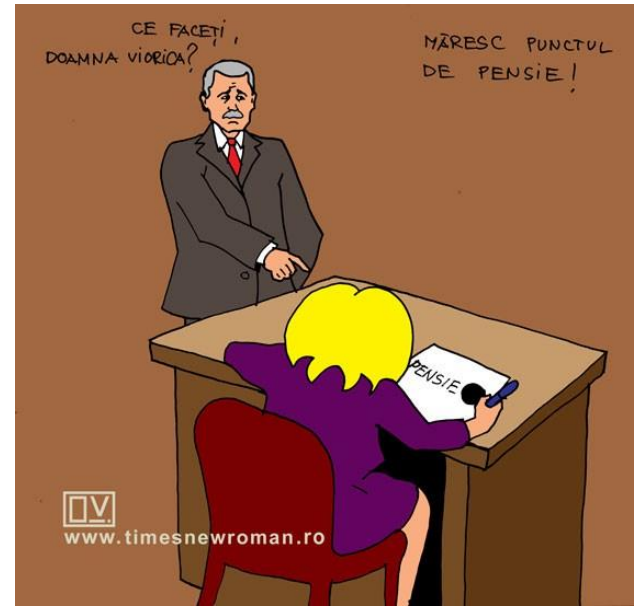

Figure 1. Q: What are you doing, Mrs. Dancila? A: I am increasing the pension dot! Source: www.timesnewroman.ro

In Figure 2, polysemy is also used both in the text and the image, through the word patriot (rom. patriot). The first meaning of this word involves an individual who loves his country (suggested by Romania's flag display on the Parliament Palace building), while the second one refers to American Patriot missiles. Humour results here from the "wrong" use of this word, which results in entering the non-bona fide communication, an unrealistic world wherein the Socialist Democratic Party (whose members insisted on adopting a law to allow Patriot ballistic missile procurement) shows its love for the country only by buying such missiles. The meaning of patriot does not come, as readers would expect, from actually accomplishing their duty for the benefit of their citizens, but from an action that could have negative effects (the missiles' direction in the cartoon does not suggest their acquisition, but targeting Romania).

This cartoon was created by Times New Roman caricaturists when, back in 2017, Liviu Dragnea, chief of the SDP, proposed the acquisition of Patriot systems. As Dragnea was often accused of following his interests and not those of the country and its citizens, this opposition between the meaning of the word patriot and its "misinterpretation," as presented in this cartoon, further increases the humorous effect. The visual symbol of patriot is the Romanian flag and the Parliament Palace on the one side, and, on the other side, a contrast is created with the Patriot missiles. Humour emerges from interpreting the idea of "being a patriot" as "attacking your country with Patriot missile systems."

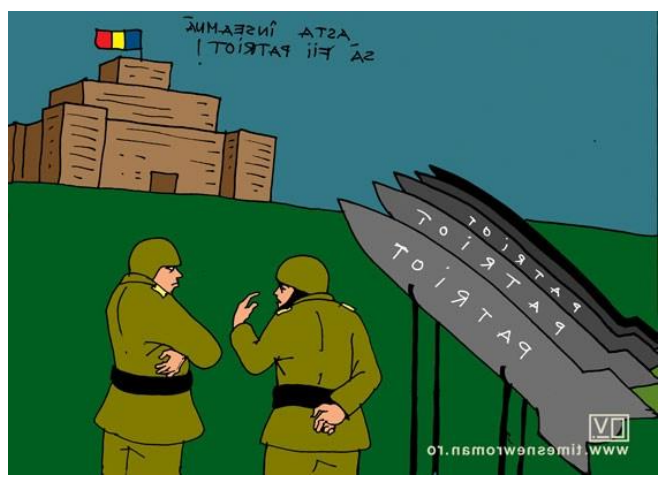

Figure 2. This is what being a Patriot means! Source: www.timesnewroman.ro

Through polysemy, caricaturists highlight their humorous intention by activating two opposed meanings, along with images supporting the ambiguity in interpretation. Interpreting 
polysemy in humorous text requires a certain effort from the reader, who is expected to distinguish between both meanings and then connect them in the context of the cartoon. The context of this cartoon involves Dragnea's announcement about buying Patriot missiles from the USA, the humorous target is the SDP's former leader, the opposed scripts are real-absurd, smart-stupid, and the logical mechanism is false analogy.

\subsubsection{Exaggeration}

Exaggeration is a mechanism extremely used for constructing cartoons. It relies greatly on the readers' background and the physical similarity of the characters and the cartoons' real-life targets. Exaggeration, the alteration of an individual or a situation through images, activates a reader's humorous interpretation and helps him create the necessary connections to find the punchline.

In Figure 3, using the verb refuse (rom. a refuza) in the context created in the cartoon (two women, Olguta Vasilescu, former Socialist Democratic Party member, and Viorica Dancila, former Prime Minister, negotiating how to address a man, President Klaus Iohannis) refers to the repeated refusal that Olguta Vasilescu received from the President, when she expressed her wish to become the minister of Home Affairs. Olguta Vasilescu and Viorica Dancila were often criticised by the media for not being able to handle some serious issues of the state, but instead for being more concerned with their appearances and their own personal interests.

Humour here comes from combining the extra-textual context (the President's repeated refusal) and a fictional story, according to which the president has been seduced by two women. The women's clothes also point to the excessive interest in their looks rather than politics. The key interpretation tool here is the visual metaphor: Dancila and Vasilescu are acting as two prostitutes, while Iohannis treats them as if they would be available for him at any time. If the reader does not have enough information about the political situation and the relationship between the represented individuals, the cartoon will not easily make sense. This highlights the idea that when it comes to political cartoons, it is not only important to find the similarities between the characters and their real referents, but also to know the events the cartoons are referring to. The readers must receive such hints towards this direction both textually and visually.

The humorous targets are both Iohannis and Vasilescu, the opposed scripts are realimaginary, the situation is president's refusal to appoint Vasilescu as Minister, and the logical mechanism is the false analogy and exaggeration.

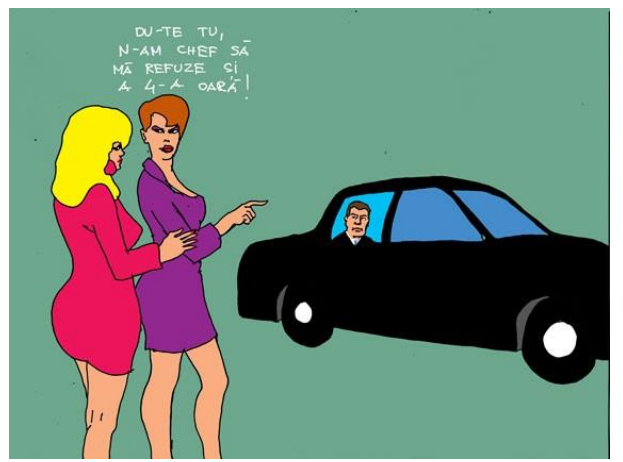

Figure 3. He's all yours! I do not want him to refuse me for the fourth time!

Source: www.timesnewroman.ro 


\subsubsection{Hyper-understanding and non-understanding}

Hyper-understanding involves "hearer's capacity to exploit the possible weak points in speaker's previous sentence, referring to it by changing the interpretation of speaker's initial meaning" (Brone, 2008: 2031, in Constantinescu, 2012: 64). In essence, hyper-understanding is an echoic use of a speaker's words. At the other side of the table, there is non-understanding, which is the wrong interpretation of a speaker's sentence/answer.

These two linguistic phenomena, which are exploiting different linguistic-conceptual set ups, are frequently used in Romanian humorous media, particularly in cartoons: simply placing hyper-understanding or non-understanding situations around important political figures makes readers laugh. The most common mechanism for these two phenomena is syllepsis.

Figure 4 was created after Viorica Dancila, the former Prime Minister, welcomed the Pope at Cotroceni in 2019. They exchanged gifts, the pope offering Dancila some books and a medal, while she gave him a watch. As the former Prime Minister is known for her grammatical mistakes, Pope's gesture was perfectly exploited by caricaturists.

Here, hyper-understanding is created through the two meanings of the verb find yourself (rom. a se regăsi). The first meaning that the reader activates is find your path/way, and the second one, which actually makes him/her laugh is identification. The hyper-understanding comes from the fact that the Pope and Viorica Dancila give this verb different meanings. Humour emerges when Pope's meaning is totally inappropriate for the context: the identification of the former Prime Minister with one of the species in the book, while Dancila gives the Pope a Bible to find his peace in it. Dancila's baffled and insecure facial expression suggests something the media often claim about her: she never knows what she is doing, because she only obeys Dragnea's orders (see above).

The target is Prime Minister Viorica Dancila, the situation is Pope's visit, the opposed scripts are real-absurd, and the logical mechanism is faulty reasoning.

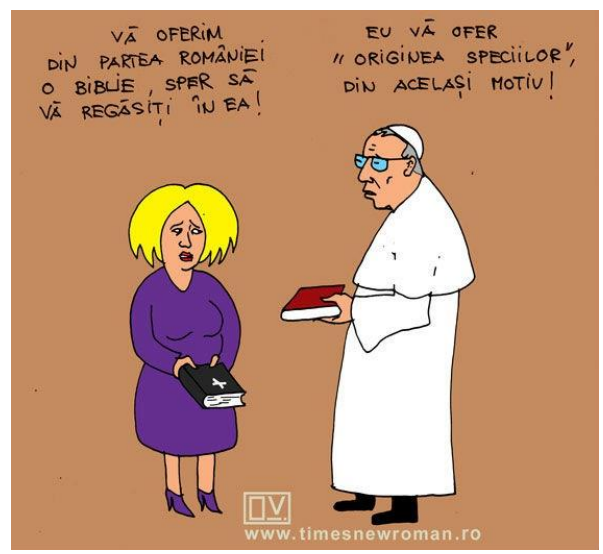

Figure 4. Viorica Dancila: We are offering you a Bible. I hope you will find your peace in it! Pope: I am offering you [the book] On the Origin of Species for the same reason!

Source: www.timesnewroman.ro

The cartoon in Figure 5 appeared in 2018, after former Prime Minister Viorica Dancila called for "unity" between the Parliament and her administration (often accused of corruption) during her Centenary speech. The visual metaphor here is: Viorica's colleagues could only be united in prison.

In Figure 5, the non-understanding phenomenon emerges from the different meanings of the word united (rom. uniți). The first meaning is join a group which shares the same ideas as you do, a group of close people, and the second one is tied. Non-understanding comes when the three policemen are actually activating the second meaning, tied, contrary to Viorica 
Dancila's expectations, tied to the relation between her party's members and the Parliament. Although the cartoon presents only the policemen's response, the Prime Minister's message can definitely be arrived at from the presented image (she got tied to her former SDP colleagues), but also from the extra-textual context, wherein the Prime Minister urged her colleagues in Parliament to be more united.

The clothes of the party members suggest their high positions in Parliament, but the fact that they look alike with regard to clothes (black suits) and facial expressions also suggests their lack of personality and firmness, as they are all considered to be the party's chief puppets. The three officers' angled positions when holding the rope suggest the difficulty in catching corrupt politicians.

The humorous target is Viorica Dancila, the situation is the speech the Romanian Prime Minister held at the Centenary celebrations where she called for unity, the opposed scripts are real-imaginary, and the logical mechanism is the faulty reasoning.

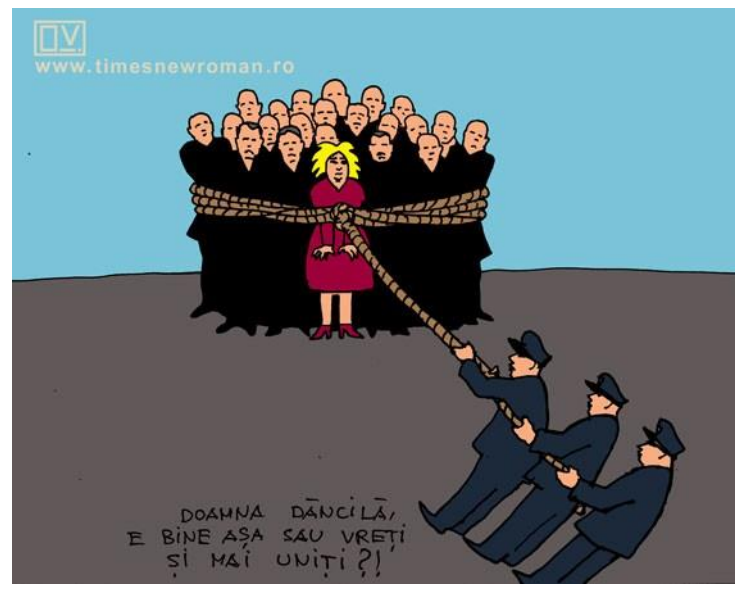

Figure 5. Mrs. Dancila, is this ok or would you like it to be even tighter?

Source: www.timesnewroman.ro

\subsection{Social issues and gossip}

Unlike political cartoons, where caricaturists want to underline different political shortcomings affecting the nation and, thereby, provoke a certain reaction among readers (to criticise and persuade them), in cartoons on social issues and gossip, the main purpose is making people laugh, ridiculing Romanian society and culture rather than blaming it. These cartoons are referring to various events spread all around the media, funny moments in Romanian people's lives which got media attention, absurd and comic situations famous people were caught in, etc. Usually, social cartoons rely on stereotypes. More specifically, they often underline individuals' inadequate behaviour and shortcomings in terms of education or, when it comes to famous people, they focus on the ridiculous situations they find themselves in. Such examples of stereotypical representations involve the complainer, the drinker, the constantly cheerful, the disreputable women, the bumpkin, and so on.

Another difference between political cartoons and the category examined here is that the first ones are much more based on the text included in the balloons, their correct interpretation needing more details about the target. As the main purpose of cartoons on social issues is ridiculing and making readers laugh, these have deeply expressive images and symbols.

As I will show, the mechanisms caricaturists use to create such cartoons are the same (implication, hyper and non-understanding, polysemy, homonymy, paronymy); however, they seem to have fewer words and more expressive pictures. 


\subsubsection{Implication}

In Figure 6, the cartoon illustrates a courtroom and refers to a process wherein the defendant gets acquitted. There are only women in the room, all with an exaggerated bust and big lips, suggesting that they have undergone plastic surgery. This cartoon refers to the media scandal created because of an Italian citizen who, without any medical or university training, pretended to be a plastic surgeon and worked in various hospitals in Bucharest.

Humour comes here both from the women's exaggerated figures and the highlighting of unrealistic events wherein the defendant gets acquitted only because he was once their doctor. Although this picture makes many people laugh, it also points to the corrupt system in Romania, wherein such actions may often happen. This cartoon does not need any additional information, as with political cartoons, because the information can be deduced just from the images. The simple exaggeration of their figures is enough to connect it to that media scandal. However, without appropriate background knowledge, the reader fails to get the humorous effect.

The opposed scripts are real-unreal, fair-unfair, the humorous target is both the Italian fake doctor and the representatives of the hospital he worked in, and the women for their vanity and interest in appearances only, the situation is the scandal brought to the surface by the media, and the logical mechanisms are implication and exaggeration.

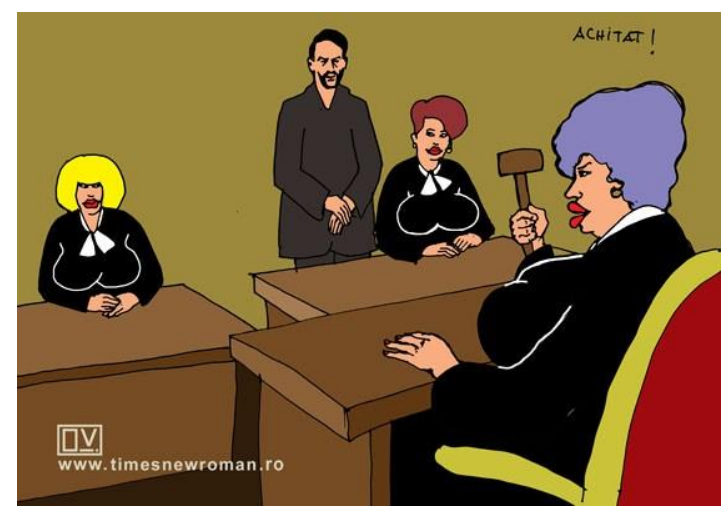

Figure 6. Acquitted! Source: www.timesnewroman.ro

In Figure 7, the cartoon alludes to the fight and defeat of Mircea Badea (a famous yet controversial Romanian TV presenter), who got knocked out, after only 5 seconds, by Teodor Constantin, a motorcyclist with whom he had fought in the past.

In this case, the caricaturists gave the reader an additional hint alluding to another moment when the TV presenter got all media's attention: he tried to copy Jean Claude Van Damme in the Volvo ad, doing the splits on two chairs. Hereof, the absence of the text is replaced by a double implication: Badea's past (identification) and his recent ridiculous event (actualization). In order words, caricaturists comprise two well-known moments of his life in one cartoon to help the reader make the proper connections and get the humorous effect, but also to show his "evolution" in terms of ridiculous moments in the Romanian showbiz environment. These two processes, identification and actualization, are triggered by the construction of the cartoon: the character's position alludes to his knock-out and the four chairs allude to his attempt to stage himself like the famous actor. The ridiculousness also comes from the fact that, even though Van Damme was doing splits on two chairs, now Badea needs four, because he has fainted. The visual metaphor here is extremely meaningful: even when he is knocked down, he still does it like Van Damme.

The opposed scripts are real-unreal, the humorous target is Mircea Badea, the situation is his knock-out, and the logical mechanisms are implication and exaggeration. 


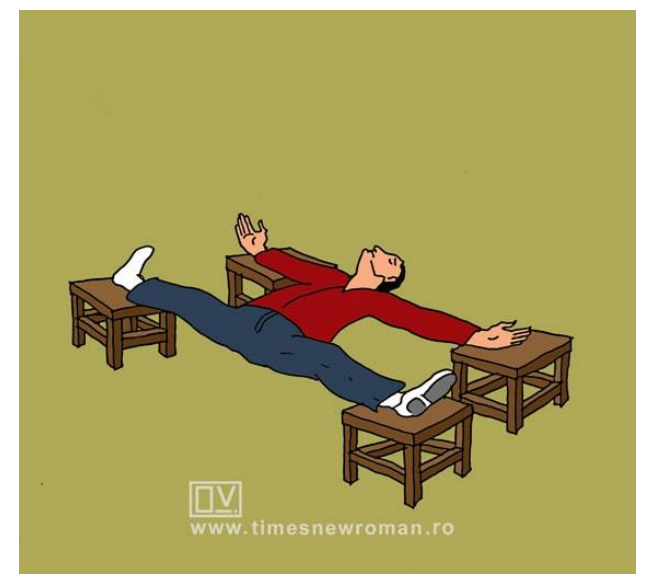

Figure 7. Source: www.timesnewroman.ro

\subsubsection{Hyper-understanding and non-understanding}

Hyper-understanding is a mechanism also used by Academia Catavencu, in a cartoon illustrating a woman pushing a car her husband is in during wintertime. The message accompanying that cartoon was: "Behind every man's back there is a strong woman!" The humour emerges from the two meanings of the words back (rom. spate) and strong (rom. puternică). The cartoon refers to the denotative meanings of these words: back as "place" and strong as "physical power." However, the propositional content in the saying refers to their connotative meanings: back, as in having someone's back, and strong, as in a firm attitude. Humour results from the denotative interpretation of a saying created by the comedian Groucho Marx, which became famous during the feminist revolutions between 1960 and 1970, and its actual implementation in day-to-day life. The characters in the cartoon are exploiting word meaning, thus causing the reinterpretation of the saying. The purpose of such a cartoon is, indeed, making readers laugh.

The opposed scripts are real-absurd, the humorous target is contemporary feminists, the logical mechanism is faulty reasoning and the exchange of roles, and the situation involves contemporary society and women's online movements suggesting that they are as strong as men.

In a different cartoon, Academia Catavencu's cartoonists used non-understanding to illustrate a woman in front of a circus trying to convince her son not to enter it, with a message saying: "Come on, dear! Let's go home! Don't we have our own circus on Romania TV?" Humour in that cartoon comes from the syllepsis of the noun circus (rom. circ). The first activated meaning is show, spectacle, as illustrated in the image, and the second one is its pejorative meaning, scandal, ridiculousness, activated by one of the characters.

Humour is triggered after attaching the idea of a show wherein the ridiculousness is the spectacle's intention, part of the artists' programme, and the shows of Romania TV, a channel where presenters' debates are seen as exaggerated, unprofessional and, sometimes, grotesque by the audience.

The opposed scripts are professionalism-dilettantism, the humorous target is Romania $\mathrm{TV}$, the people working for them, and their audience, the situation involves Romania TV's exaggerated news and the logical mechanism is exaggeration and false analogy.

\section{Conclusion}

The purpose of this paper was to analyse the mechanisms used to create humour in Romanian media cartoons, specifically in the Times New Roman and Academia Catavencu 
websites. I have analysed political cartoons and cartoons referring to social issues and gossip to show the difference in their construction depending on their topics. I have observed that political cartoons' content is more complex than cartoons on social issues, as getting the right interpretation of a cartoon targeting political events/situations or politicians requires some extratextual information. Otherwise, humour fails. The cartoons targeting everyday events use powerful symbols, while political cartoon images are always accompanied by texts, aiming at directing the reader towards a specific interpretation. As for cartoons on social issues, many times, images are enough to convey the intended meaning, because the intention of caricaturists is not to criticise or push the audience towards critical thinking, but to make them laugh. Of course, for both political and social issues, readers of cartoons must have previous information (shared knowledge) about the targeted people/situations. Yet, I observed that the humorous effect in cartoons on social issues emerges relatively easier than in the political ones. This may also result from the fact that political cartoons are pointing to some shortcomings directly affecting the society (for example, politicians' state of mind and decisions), while those referring to famous people in the Romanian public sphere primarily aim to make people laugh.

\section{Acknowledgements}

I would like to thank the Times New Roman editors for granting me permission to reproduce their cartoons and also the EJHR editors for guiding me in editing this paper and bringing it to this form.

\section{Humorous News Sources}

www.timesnewroman.ro (https://www.timesnewroman.ro/ovi)- last date: 30/03/2020 www.academiacatavencu.ro (http://www.academiacatavencu.info/cauta/caricaturi)- last date: $30 / 03 / 2020$

\section{References}

Alousque N (2014) 'Pictorial and verbo-pictorial metaphor in Spanish political cartooning', Clac Circulo de linguistica aplicada a la communication 57, pp. 59-84.

Alousque N. (2013). "Visual metaphor and metonymy in French political cartoons", in Revista Espanola de Linguistica Aplicada 26, pp 365-384.

Attardo, S. (2001). Humorous Texts: A Semantic and Pragmatic Analysis, Berlin/ New York: Mouton de Gruyter.

Bounegru, L. and Charles F. (2011). 'Metaphors in editorial cartoons: representing the global financial Crisis'. Visual Communication 10 (2), pp. 209-229.

Brock, M. (2018). 'Political satire and its disruptive potential: irony and cynicism in Russia and the US', Culture, Theory and Critique 59 (3), pp. 281-298.

Constantinescu, M. (2012). Umorul politic românesc în perioada comunistă. Perspective lingvistice, Bucharest: Editura Universității din București.

Dawkins, R. (1976). The Selfish Gene, New York, Oxford University Press.

El Refaie, E. (2004). 'Our purebred ethnic compatriots: irony in newspaper journalism', Journal of Pragmatics 37, pp. 781-797.

Hempelmann, C. \& Samson A. (2008). 'Cartoons: Drawn jokes?' in Raskin, V. (ed.), The Primer of Humor Research, 609-640. Berlin/New York: Mouton de Gruyter. 
Hussein. I. (2019). 'Analyzing political cartoons in Arabic-language media after Trump's Jerusalem move: A multimodal discourse perspective', International Journal of Business, Human and Social Sciences 13 (4): 451-465.

McClennen S. \& Maisel R. (2014). Is Satire Saving our Nation? Mockery and American Politics, New York: Palgrave Macmillan.

Mendez-Ga ${ }^{a}$ de Paredez, E. (2013). 'Discursive mechanism of informative media in Spanish media', in Ruiz Gurillo L \& Alvarado Ortega M. B. (eds.), Irony and Humour. From Pragmatics to Discourse, Amsterdam/Philadelphia: John Benjamins, pp. 85-107.

Newman, M.C. (2010). 'The Daily Show and meta-coverage: How mock news covers the political communications system', The Elon Journal of Undergraduate Research in Communications 1 (2), pp. 5-16.

Saltzman, J. (2007). 'Fostering fake news stories', USA Today 135 (2740).

Stockwell, Stephen. (2004). 'Reconsidering the fourth estate: the functions of infotainment', Paper presented at the conference of Australian Political Studies Association, University of Adelaide.

Tsakona, V. (2009). Language and image interaction in cartoons: Towards a multimodal theory of humour', Journal of Pragmatics 41, pp. 1171-1188. 